\title{
Bilateral hearing loss following a retrobulbar block
} [Surdité bilatérale à la suite d'un bloc rétrobulbaire]

\author{
Ronald B. George MD, Jason Hackett RRT
}

Purpose: Regional anesthesia is the most commonly used ophthalmological anesthetic technique in Canada and the United States. Brainstem anesthesia is not an uncommon complication of retrobulbar blocks. Anesthesiologists are a prominent element in the ophthalmology suite, in part due to the complications possible with regional anesthesia. This is the first reported case of complete bilateral hearing loss following a retrobulbar block.

Clinical features: A 46-yr-old male with type I diabetes mellitus presenting for ophthalmological surgery had a retrobulbar block performed by the ophthalmologist. Local anesthetic was injected through a $25 \mathrm{G}, 1.5$ inch needle, entering the orbit inferiorly on the temporal third of the lower lid. Shortly after the block was completed the patient experienced sudden hearing loss. On examination the hearing loss appeared to be complete and bilateral. The patient was alert and oriented; the remainder of the cranial nerve exam was normal. The patient's hearing loss gradually improved and three hours after the block his hearing had subjectively returned to normal.

Conclusion: Brainstem anesthesia is not a rare complication of regional anesthesia for ophthalmological surgery. Symptoms include confusion, mental agitation, dizziness, blurred vision or blindness, ophthalmoplegia, deafness, tinnitus, dysphagia, dysarthria, respiratory depression to apnea, and/or limb paralysis. A connection between the subdural and subarachnoid spaces and the optic sheath exists. The effect on the central nervous system depends upon the amount of local anesthetic injected and the area to which it spreads.

Objectif: L'anesthésie régionale est la technique anesthésique ophtalmologique la plus utilisée au Canada et aux États-Unis. L'anesthésie du tronc cérébral n'est pas une complication rare des blocs rétrobulbaires. Nous présentons le premier cas connu de surdité bilatérale totale après un bloc rétrobulbaire.

Éléments cliniques: Un homme de 46 ans atteint de diabète de type I a subi une opération ophtalmologique sous anesthésie rétrobulbaire réalisée par l'ophtalmologiste. L'anesthésique local a été injecté avec une aiguille $25 \mathrm{G}$, de $I, 5$ pouce, introduite dans la partie inférieure de l'orbite au tiers temporal de la paupière inférieure. Peu après l'installation du bloc, le patient a perdu soudainement l'audition. À l'examen, la surdité semblait totale et bilatérale. Le patient était éveillé et lucide; le reste de l'examen des nerfs crâniens était normal. L'audition s'est graduellement améliorée et, trois heures après le bloc, semblait subjectivement revenue à la normale.

Conclusion : L'anesthésie du tronc cérébral n'est pas une complication rare de l'anesthésie régionale en chirurgie ophtalmologique. Elle se manifeste par la confusion, l'agitation mentale, le vertige, la vison floue ou la cécité, l'ophtalmoplégie, la surdité, les acouphènes, la dysphagie, la dysarthrie, la dépression respiratoire allant jusqu'à l'apnée et/ou la paralysie des membres. II y a une connexion entre les espaces sous-dural et sous-arachnoïdien et la gaine optique. L'effet sur le système nerveux central dépend de la quantité d'anesthésique local injecté et de l'étendue de sa diffusion.

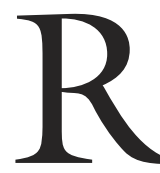
EGIONAL anesthesia is the most commonly used ophthalmological anesthetic technique in Canada and the United States. Retrobulbar blocks have been frequently used since its first description by Knapp in $1884 .{ }^{1}$ Complications of a retrobulbar block include retrobulbar hemorrhage, globe perforation, blindness, brainstem anesthesia, and various ocular muscle complications. Brainstem anesthesia, in one form or another, is thought to occur in approximately 1:500 patients. ${ }^{1}$

\section{Case presentation}

The patient involved provided written informed consent for publication of this report and institutional Research Ethics Board approval was obtained. A 46-yr-old male suffering from proliferative diabetic retinopathy, traction retinal detachment, and vitreous

From the Department of Anesthesia, Queen Elizabeth II Health Sciences Centre, Dalhousie University, Halifax, Nova Scotia, Canada. Address correspondence to: Dr. Ronald B. George, Department of Anesthesia, Room 5452 Halifax Infirmary, Queen Elizabeth II Health Sciences Centre, 1796 Summer Street, Halifax, Nova Scotia B3H 3A7, Canada. Phone: 902-473-2325; Fax: 902-473-9454;

E-mail: rbgeorge@eastlink.ca

This manuscript was completed without funding. Accepted for publication March 10, 2005. Revision accepted July 7, 2005. 
hemorrhage presented to our institution for ophthalmological surgery. The patient's past medical history consisted of type I diabetes mellitus, hypertension, hyperlipidemia, chronic pancreatitis secondary to previous alcohol abuse, gastric esophageal reflux disease, smoking, depression, and anxiety. Previous general and regional anesthetics, including a previous retrobulbar block, were uncomplicated. His medications included insulin, ramipril, temazopam, atorvastatin, amitriptyline, respiridone, carbamazepine, ranitidine, and domperidone. He had no known medication allergies.

Preoperatively blood pressure was $138 / 94 \mathrm{mmHg}$, pulse rate $112 \mathrm{~min}^{-1}$, and respiratory rate $16 \mathrm{~min}^{-1}$, his oxygen saturation breathing room air was $99 \%$. Following iv cannulation, the patient was given 1.5 mg iv midazolam, $25 \mu \mathrm{g} i v$ fentanyl and prepared for the retrobulbar block to be performed by the ophthalmologist. Prior to commencing the block, the patient's vital signs were: pulse rate $104 \mathrm{~min}^{-1}$, blood pressure $162 / 98 \mathrm{mmHg}$, oxygen saturation $99 \%$ on $4 \mathrm{~L} \cdot \mathrm{min}^{-1}$ oxygen via facemask.

The ophthalmologist performed the retrobulbar block with the eye in the primary position looking superiorly. Nine millilitres of a mixture of $1 \%$ xylocaine and $0.375 \%$ bupivacaine without epinephrine were injected through a $25 \mathrm{G}, 1.5$ inch $(38 \mathrm{~mm})$ needle. The needle entered the orbit inferiorly on the temporal third of the lower lid. As the patient had insufficient ocular muscle blockade, a second injection of 5 $\mathrm{mL}$ of $2 \%$ xylocaine was administered which rendered the eye akinetic. Approximately five minutes after the second injection the patient's speech was slurred and he appeared confused. Eight to ten minutes after the block was completed, the patient had sudden hearing loss. On gross examination the hearing loss appeared to be complete and bilateral. The patient was hypertensive, $210 / 120 \mathrm{mmHg}$, and tachycardic, 104 $\mathrm{min}^{-1}$. He was treated with esmolol $\left(0.5 \mathrm{mg} \cdot \mathrm{kg}^{-1} i v\right)$. The patient's blocked eye was akinetic with no light reflexes. The contralateral eye had appropriate motor function. A previous vitrectomy rendered the patient's contralateral pupil non responsive, and was therefore no aid in diagnosis. The patient was able to read questions with his glasses on, and complained of no vision loss in the contralateral eye.

Twenty minutes after the onset of bilateral deafness, there was a witnessed decrease in respiratory effort and eventually apnea. Oxygen saturation decreased to $85 \%$ on $4 \mathrm{~L} \cdot \mathrm{min}^{-1}$ oxygen via facemask. The patient was bag-mask ventilated for approximately three minutes and was then able to maintain normal oxygen saturation with supplemental oxygen. At this point the intended ophthalmology procedure was cancelled.
After the short-lived respiratory depression, the patient was talking loudly and his speech was clearly slurred. Neurological examination at that time revealed the patient to be alert and oriented. The bilateral hearing loss was unchanged. The remainder of the cranial nerve exam was normal. Cerebellar examination was within normal limits.

One hour after the onset of hearing loss, the patient noticed partial return of his hearing. Prior to transfer to the postanesthesia care unit his vital signs were as follows; blood pressure 146/52 $\mathrm{mmHg}$, pulse 94 $\mathrm{min}^{-1}$, and oxygen saturation $99 \%$ on $2 \mathrm{~L} \cdot \mathrm{min}^{-1}$ of oxygen. The patient's hearing loss gradually improved and three hours after the block his hearing had subjectively returned to normal.

\section{Discussion}

Since Knapp's first description of the retrobulbar block in 1884, it has become commonplace in North American ophthalmological surgery. ${ }^{1}$ Although ophthalmologists are performing the vast majority of blocks, anesthesiologists are still a prominent element in the ophthalmology suite in part due to the complications possible with a retrobulbar block. Some of the more serious complications include retrobulbar hemorrhage, globe perforation, blindness, brainstem anesthesia, and various ocular muscle complications. ${ }^{1}$ Complications occur secondary to direct injury from the needle, local anesthetic allergy or systemic toxicity, intra-arterial injection, and intra-dural injection.

The retrobulbar block generally produces excellent anesthesia and akinesis by blocking cranial nerves III, IV and VI, as well as ciliary nerves. The original Atkinson retrobulbar technique involved turning the eye upward and nasally to aid in keeping the muscles and fascia displaced away from the needle. This was later dismissed as a dangerous technique as the optic nerve and ophthalmic artery rotate into the path of the needle. Currently the most accepted technique involves maintaining primary gaze, penetrating the lower temporal orbital margin, and advancing a 1.25 inch $(31 \mathrm{~mm})$ needle parallel to the plane of the orbit until the tip of the needle passes the equator of the globe. Then the needle is directed upward and medially to approach the midsagittal plane of the globe.

Brainstem anesthesia is thought to complicate approximately one in every 500 retrobulbar blocks. It is the result of an intra-dural injection of local anesthetic. Symptoms include confusion, mental agitation, dizziness, blurred vision or blindness, ophthalmoplegia, deafness, tinnitus, dysphagia, dysarthria, respiratory depression to apnea, and/or limb paralysis. ${ }^{2-10}$ Hypotension and bradycardia have been observed with 
brainstem anesthesia, but more commonly hypertension and tachycardia result. ${ }^{6}$ The hypertension and tachycardia are either due to vagolysis or blockage of the carotid sinus reflex via the glossopharyngeal nerve. ${ }^{3}$

The optic nerve is covered by three cerebral membranes as it travels from the brain, the pia mater, the arachnoid, and an outer sheath from the dura mater. They are separated from each other and communicate with the subdural and subarachnoid cavities. ${ }^{11}$ In 1969, Reed et al. ${ }^{12}$ performed orbitography on a patient to investigate possible intraorbital tumour involvement. Shortly after completion of the procedure the patient reported loss of vision; subsequent radiographs showed the contrast material in the intracranial subdural space with no apparent spread to the subarachnoid space. A cadaveric study showed progression of radiopaque dye along the subdural space posteriorly to the optic chiasm, and eventually surrounding the pons and midbrain. ${ }^{13}$ A connection with the subarachnoid space was later shown by Wang et al., ${ }^{14}$ who injected cadaver optic sheaths with methylene blue. The dye tracked along the optic nerve and then appeared in the subarachnoid space in the middle cranial fossa's chiasmatic cisterns. Lastly, as a means of confirming the cause of a case of brainstem anesthesia following a retrobulbar block, Kobet ${ }^{15}$ retrieved high levels of xylocaine from the cerebral spinal fluid.

The optic sheath is continuous with the subdural and subarachnoid space surrounding the brainstem and cranial nerves. A needle piercing the optic sheath gives the local anesthetic a conduit to the brainstem. The tachycardia, hypertension, apnea and hearing loss experienced by our patient are a direct consequence of local anesthetic tracking along the optic sheath to the brainstem and cranial nerves, specifically cranial nerves VIII and X (Figure). The sporadic onset of the signs and symptoms of brainstem anesthesia are likely due to injection into the subdural space then diffusion into the subarachnoid space near the effect site of the brainstem. The effect on the central nervous system is dependent upon the amount of local anesthetic injected and the area to which it spreads.

In the case of this patient, it is likely that the needle was within the optic sheath at some point during the procedure and an unknown quantity of local anesthetic was injected into the subdural space. The inadvertent subdural injection may have been due to use of a 1.5 inch $(38 \mathrm{~mm})$ needle rather than the recommend 1.25 inch $(31 \mathrm{~mm})$ needle. Katsev et al. ${ }^{16}$ measured the orbital depth of a series of human skulls in relation to the length of commonly used needles for retrobulbar anesthesia. They recommended that the 1.25 inch (31 $\mathrm{mm}$ ) needle is safer in regards to optic nerve penetra-

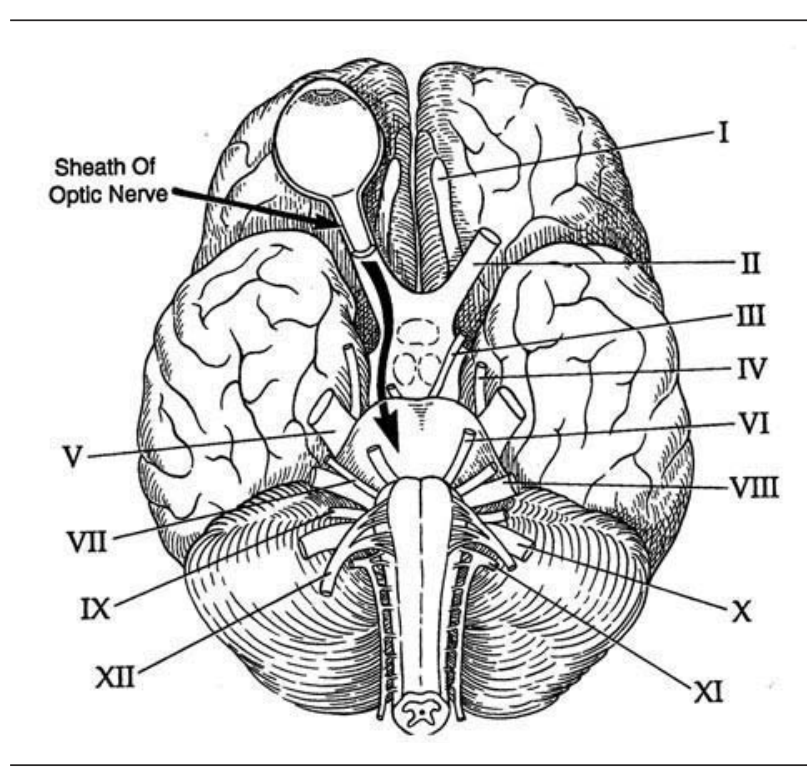

FIGURE The path that local anesthetics might follow if injected into the subdural space. Reprinted from Ophthalmology, 94(6), Javitt JC et al., ${ }^{10}$ Brain stem block after retrobulbar injection, 718,1987 , with permission from the American Academy of Ophthalmology.

tion and adequate for anesthesia administration.

Several alternative methods of local anesthesia for ophthalmologic surgery are currently in use, including peribulbar and topical anesthesia. ${ }^{1}$ Topical anesthesia is economical, administered without pain, allows for instant visual rehabilitation, and provides complete optic analgesia. ${ }^{17,18}$ Complicated cataract surgery and trabeculectomy for glaucoma have been performed safely and effectively with topical anesthesia. ${ }^{17-19}$ When feasible, alternatives to the retrobulbar block should be considered.

Fortunately, the patient's hearing returned completely. He went on to have his surgery completed in the weeks following this incident. The surgery was completed under a retrobulbar block without any complications. This case is another demonstration that the complications of retrobulbar anesthesia are potentially serious and life threatening. The presence of an anesthesiologist in the ophthalmology operating suite is still warranted but does not exempt physicians who perform this technique from being appropriately trained in matters of resuscitation and airway management. 


\section{References}

1 Wong $D H$. Regional anaesthesia for intraocular surgery. Can J Anaesth 1993; 40: 635-57.

2 Hamilton RC. Brain stem anesthesia following retrobulbar blockade. Anesthesiology 1985; 63: 688-90.

3 Hamilton RC. Brain-stem anesthesia as a complication of regional anesthesia for ophthalmic surgery. Can J Ophthalmol 1992; 27: 323-5.

4 Rosen WJ. Brainstem anesthesia presenting as dysarthria. J Cataract Refract Surg 1999; 25: 1170-1.

5 Nicoll JM, Acharya PA, Ablen K, Baguneid S, Edge $K R$. Central nervous system complications after 6000 retrobulbar blocks. Anesth Analg 1987; 66: 1298-302.

6 Ahn JC, Stanley JA. Subarachnoid injection as a complication of retrobulbar anesthesia. Am J Ophthalmol 1987; 103: 225-30.

7 Mercereau DA. Brain-stem anesthesia complicating retrobulbar block. Can J Ophthalmol 1989; 24: 159-61.

8 Castillo A, Lopez-Abad C, Macias JM, Diaz D. Respiratory arrest after $0.75 \%$ bupivacaine retrobulbar block. Ophthalmic Surg 1994; 25: 628-9.

9 Wittpenn JR, Rapoza P, Sternberg P Jr, Kuwashima L, Saklad J, Patz A. Respiratory arrest following retrobulbar anesthesia. Ophthalmology 1986; 93: 867-70.

10 Javitt JC, Addiego R, Friedberg HL, Libonati MM, Leahy JJ. Brain stem anesthesia after retrobulbar block. Ophthalmology 1987; 94: 718-24.

11 Williams PL, Warwick R, Dyson M, Bannister LH. Gray's Anatomy, 37th ed. New York: Churchill Livingstone; 1989.

12 Reed JW, MacMillan AS Jr, Lazenby GW. Transient neurologic complication of positive contrast orbitography. Arch Ophthalmol 1969; 81: 508-11.

13 Drysdale DB. Experimental subdural retrobulbar injection of anesthetic. Ann Ophthalmol 1984; 16: 716-8.

14 Wang BC, Bogart B, Hillman DE, Turndorf $H$. Subarachnoid injection--a potential complication of retrobulbar block. Anesthesiology 1989; 71: 845-7.

15 Kobet $K A$. Cerebral spinal fluid recovery of lidocaine and bupivicaine following respiratory arrest subsequent to retrobulbar block. Ophthalmic Surg 1987; 18: 11-3.

16 Katsev DA, Drews RC, Rose BT. An anatomic study of retrobulbar needle path length. Ophthalmology 1989; 96: 1221-4.

17 Jacobi PC, Dietlein TS, Jacobi FK. A comparative study of topical vs retrobulbar anesthesia in complicated cataract surgery. Arch Ophthalmol 2000; 118: 1037-43.

18 Zabriskie NA, Abmed II, Crandall AS, Daines B, Burns TA, Patel BC. A comparison of topical and retrobulbar anesthesia for trabeculectomy. J Glaucoma 2002; 11 : 306-14.

19 Ahmed II, Zabriskie NA, Crandall AS, Burns TA, Alder SC, Patel BC. Topical versus retrobulbar anes- thesia for combined phacotrabeculectomy. Prospective randomized study. J Cataract Refract Surg 2002; 28: 631-8. 